\title{
Teaching Almost Natural Things
}

\author{
FAYSAL TABBARAH \\ American University of Sharjah
}

\begin{abstract}
The paper problematizes the teaching about nature in undergraduate architecture education at a time of an increasing environmental crisis. Looking outside of contemporary academia and the discipline's response to this crisis through the lens of ecological ethics, the paper describes a teaching pedagogy that challenges how most contemporary undergraduate architecture education teaches about nature in a way that reinforces the hegemony of the nature/society binary that seems implausible and irrelevant with the advent of the Anthropocene. The paper describes a teaching pedagogy that is deployed in various curricular forms (Studio, seminar, independent research) that asks students to think about architecture as an Almost Natural condition that rejects traditional geometric hierarchies, linear part-towhole relationships, pattern making, and precision, in favor of tactical organizations a blurring of part and whole, deep textures, and the gestural.
\end{abstract}

\section{INTRODUCTION}

The emergence of the Anthropocene and its unprecedented effects on the planet's ecology has forced the industries concerned with the built environment to confront a fundamental ethical responsibility, especially as the construction industry is in itself culpable in this ongoing environmental crisis $^{1}$. Examples of the industry's response include the establishing of the U.S Green Building Council (USGBC) in 1993 with a mission to raise awareness about sustainable practices in the construction industry. This has been followed by the establishing of LEED in 2000, which is has been acting mainly as a certification program for the construction industry ${ }^{2}$, and has also migrated globally across borders. The establishing of LEED in 2000 has directly led to an emerging focus on Sustainable Architecture in both academia and practice, and many a school is looking for faculty members specialized in sustainable design. Countries outside the United States have also been racing to set up their own regional versions. While positive in spirit, sustainable and green architecture has become an increasingly codified practice through the pervasiveness of both LEED and off-the-shelf analysis software that allow designers to predict many aspects of building performance early in the design stages. While pioneering figures in this movement such as William McDonough have praised the codification of sustainable practices in construction, he has indicated that working solely in this mode cannot usher a much needed paradigm shift in design and construction ${ }^{3}$.
The codification and subsequent commodification of sustainable design practices is an primary critique of this mode of practice and teaching because while a paradigm shift in how we might design and build in the Anthropocene is absolutely and undeniably required, contemporary environmental ethics within large parts of the practice have transformed into aesthetic drivers. Basically, there is an emerging commercially driven LEED style supported up by construction, maintenance and building performance data. Subsequently, this creates a binary within the discipline and academia; architects and designers not explicitly dealing with issues of sustainable design, energy consumption, different types of mechanical building performances, efficiency and optimization are implicitly branded as unethical ${ }^{4}$.

It is naive to imply that the advent of LEED and related sustainable building practices have not raised awareness of the relationship between the built environment and climate change, neither that the codification of methods of construction, materials, and building systems is not aimed at mitigating the negative aspects of this relationship. However, they fall short in two ways. Firstly, almost two decades after the integration of these issues into practice, architecture must now look green. Architecture has become more commercially viable for looking green. Apparently, it is the only right thing to do; looking green is ethically better ${ }^{5}$. This implicit flattening of ethics and aesthetics is highly problematic. This is not surprising given the popularity of the relatively new field of study of environmental ethics, where the questions of how the public must conduct its relationship with things non-human has extended from an anthropocentric view point towards a more encompassing relationship between human beings and Nature ${ }^{67}$. Second, while these practices are attempting to affect change, or potentially a paradigm shift, in the construction industry, they fail in addressing spatial concerns. How might be construct in the Anthropocene is definitely being addressed to varying degrees, but how might we conceive of space, and inhabit space, is left largely out of the conversation. Focusing the conversation and actions on skins, building systems and methods of construction does not allow for questions of a relevant space type to be addressed.

This paper argues that a more productive search for an ethical consciousness in architecture can and should occur within academia, where the relationship between the built environment and the natural environment can be introduced to students as an integral part of their education. Thus, this 


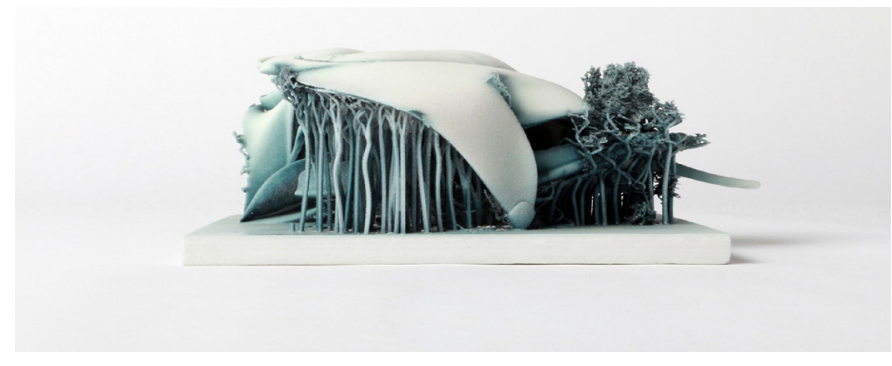

Figure 1: Residential project exploring the notion of misfit assemblies. Here, the misfitting is amongst different kinds of geometries (Volumes and lines).

paper offers a critique and a response to the ways in which nature continues to be approached within undergraduate architectural education vis-à-vis advances in digital design technology, and digital fabrication tools.

\section{AN ARCHAIC NATURE/SOCIETY BINARY}

The pedagogy deployed in architecture studios and digital design seminars described below draws on the work of the environmental sociologist William Freudenburg. Specifically, the pedagogy explores his text on the conjoined constitution between nature and society where he argues for a blurring of the boundaries between the physical (i.e. natural) and the social (i.e. human-made). Freudenburg rejects the three ways in which conventional sociology has traditionally viewed nature. The three rejected categories include (a) Considering nature as completely separate and having little to not impact on society; (b) Placing nature and society on a hierarchical scale where one is given primacy over the other; (c) Viewing nature and society as co-equal and balanced. As Freudenburg explains, viewing nature as separate, superior, subservient or balanced implies an explicit othering, that nature and society are constructed separately. His alternative, the notion that nature and society exist as two parts of a conjoined constitution, assumes that there is little difference between nature and society in that what we might think of one is heavily influenced by the other ${ }^{8}$, that they are not constructed separately but simultaneously within the same conceptual and material space. Beginning from this theoretical springboard, the teaching pedagogy described below explores this conjoined constitution between nature and society through the active blurring and subverting of the archaic understanding of nature as a detached and homogeneous thing that lies outside of the realm of the built environment, an other to be framed for marveling at, or even worse, to be exploited.

From an architectural standpoint, this paper views that the othering of nature in practice and academia is problematic in three main ways. First, and most obviously, because it recreates a general and problematic power structure where the negative environmental effects of construction are neglected. Second, an othering that creates a power structure, as described through Freudenburg's work above, has also created a condition where aesthetic and ethics have been flattened. Third, because it precludes arriving at spatial solutions for living in today's complex and flattened environmental and urban condition.

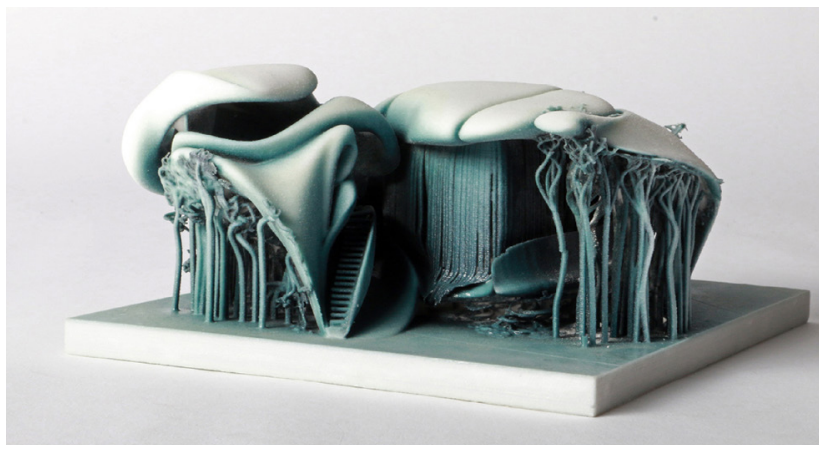

\section{THE BINARY IN ARCHITECTURE EDUCATION}

Most of contemporary undergraduate architecture education deals with the question of nature within the assumption of an archaic and failing nature/society binary. This results in teaching about nature in two simultaneous modes: (a) Site planning/ landscape architecture courses, and (b) In studios and seminars focused on sustainable building design. The first mode has found its way into academia from the world of licensing, with $N A A B$ requiring students to have the "ability to respond to site characteristics, including urban contexts and developmental patterning, historical fabric, soil, topography, ecology, climate, and building orientation." ${ }^{\prime \prime}$

This ability is usually delivered in the form of required site planning or landscape design courses within the core curriculum sequence, where the lessons learned span the spectrum between the poetics of nature in architecture history to the technical knowledge needed to conduct field surveys. The introductory paragraph to Kevin Lynch and Gary Hack's seminal Site Planning describes it as "the art of arranging structures on the land and shaping the spaces between." Primary, it seems, is the anthropocentric view of putting something on the land, and in second place comes the shaping of what results from the first violent act.

The second mode of teaching occurs under the umbrella of green or sustainable design, which typically takes place within the design studio environment. While the first mode is a response to licensing, the second mode is a response to commercial forces within industry, such as the pervasive proliferation of LEED. There is some degree of pressure on both students, and to some extent teachers, to make sure there is employability after graduation, and naturally, knowledge of the industry's norms is important in these scenarios.

Both modes of operation, in their teaching about nature and how to take care of it create a power structure where the human agent/architect is a (weak) custodian of nature. In fact, the ways in which this power structure is set up is not different to the structures that Freudenburg rejects above. These modes of teaching assume long standing othering of nature where architecture is designed around a nature that is either separate, superior, subservient or balanced. This othering implicitly 

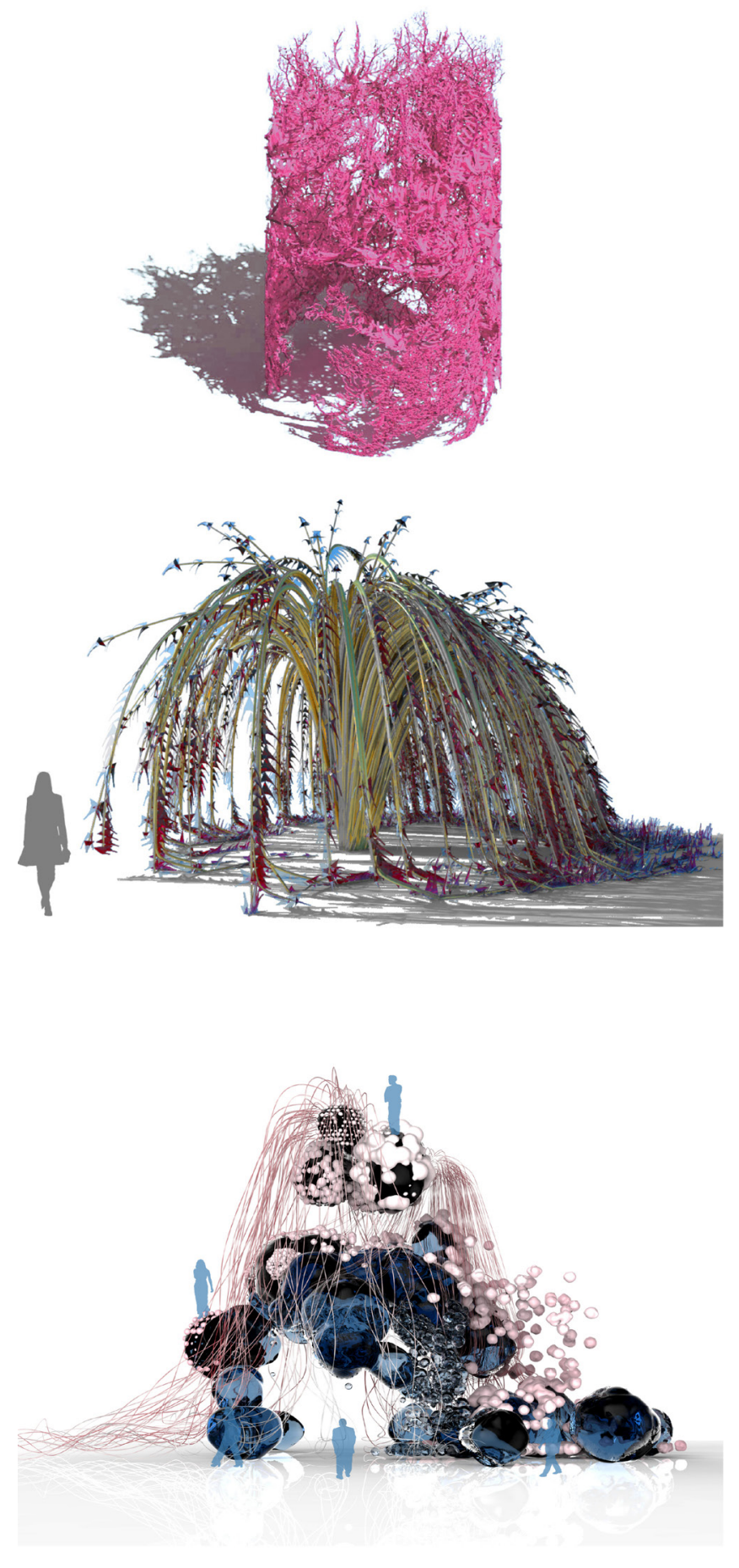
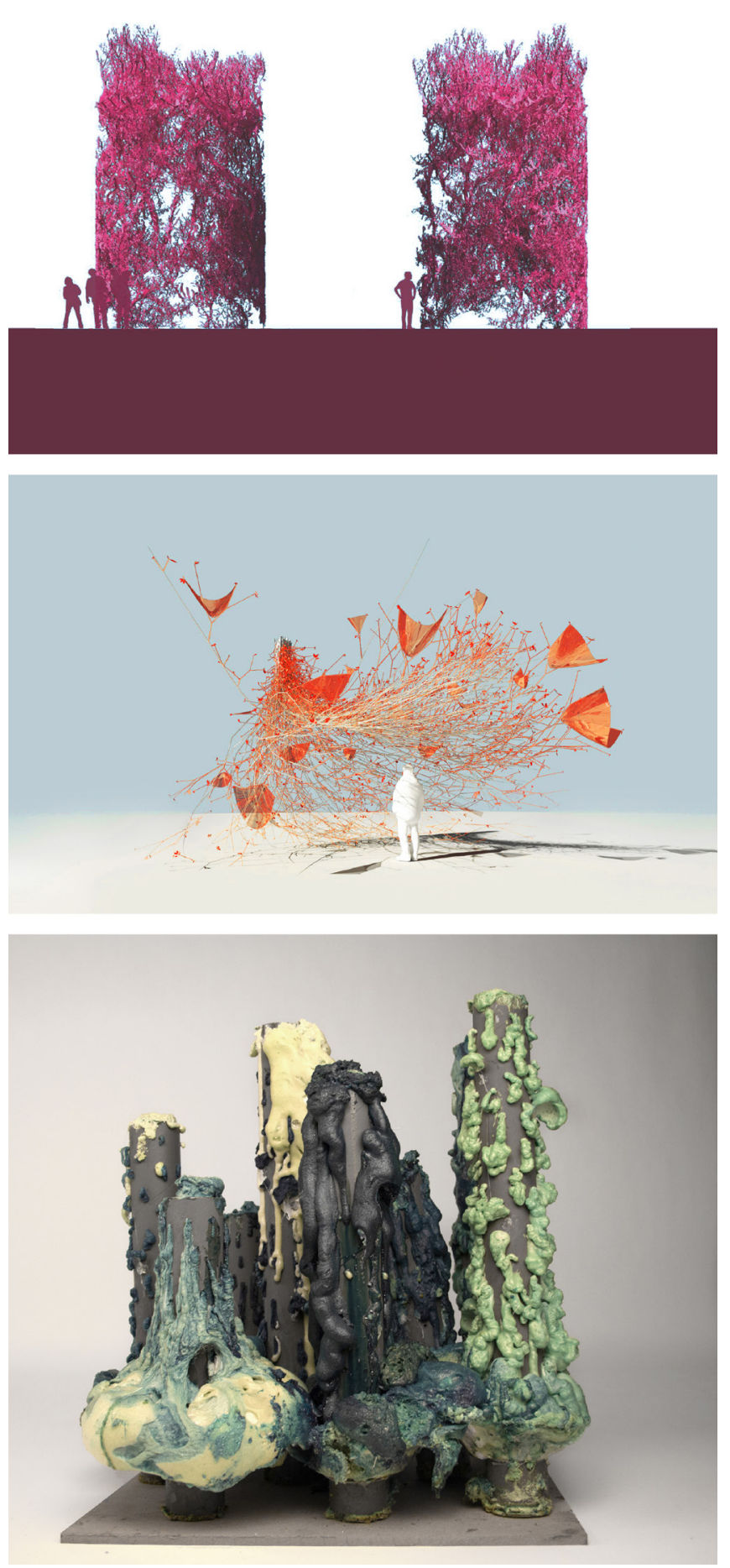

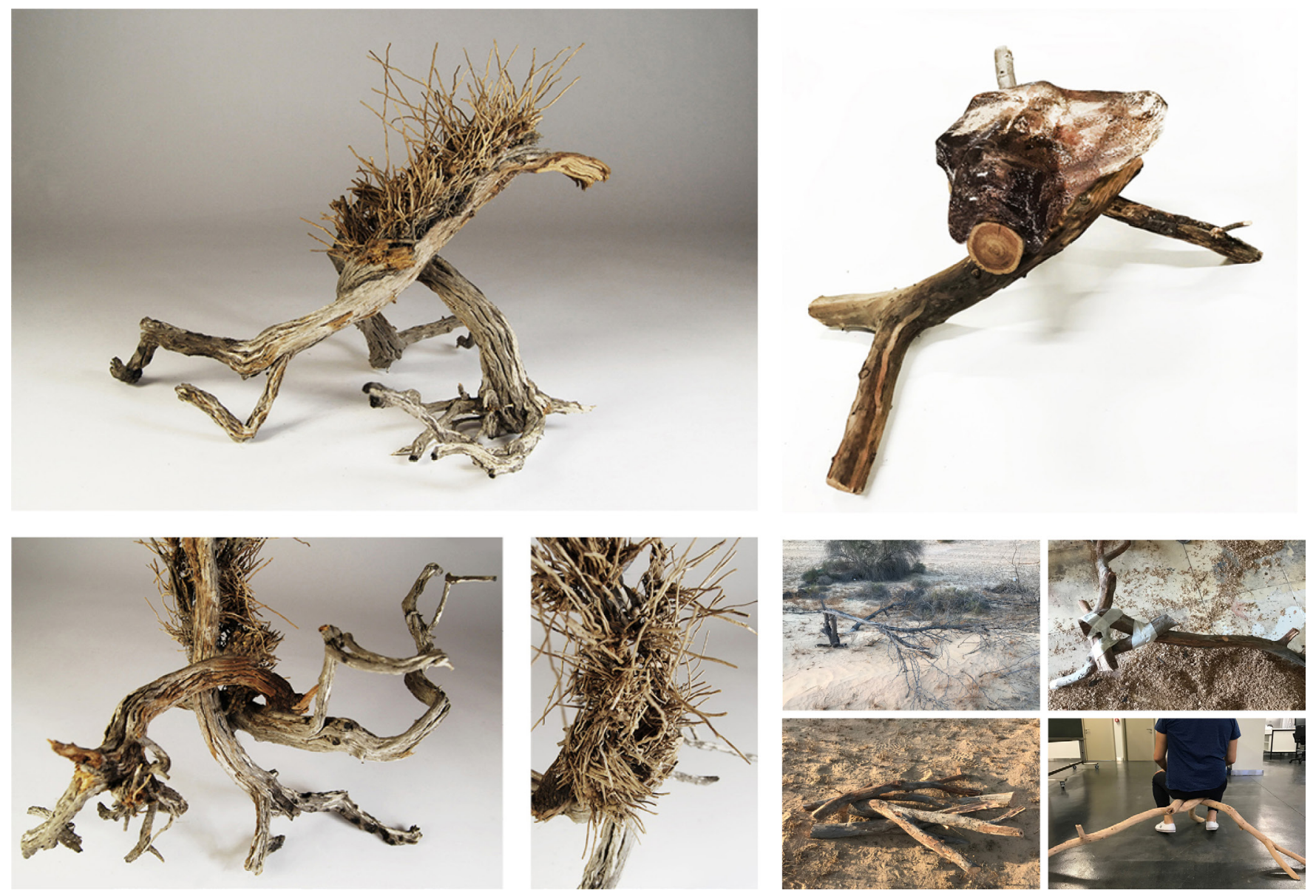

Figure 3: A project exhibiting a mis-fitting and imprecise attitude to aggregating fallen timber members into a functional chair using a reciprocal frame systems as awell as a locking mechanism in the form of the seat.

rejects the potentialities that might arise from a blurring between nature and society. The ambition implicit in the teaching pedagogy described below is that it aims at uncovering what kind of paradigm shift in the production of space can occur through an active blurring between nature and architecture. Anecdotally, a line of inquiry from the canon that is posed to the students is to reject the understanding of the Parthenon as an object in a field and as an extension of the land it rises from. While this is not a novel reading on its own, but the contemporary fascination with object conditions has rendered this reading invisible.

The solutions to the environmental crisis that come from within architecture must confront the consistent and overarching aesthetic agenda that they produce. That a layman can point to a building and call it green indicates the strong aesthetic that is being produced by such practices. The othering of nature which lead to the subversive collapse of ethics and aesthetics, is a very problematic trope as it begins to place aesthetic experiences as ones that have to be measured against an ethical criteria. This has no underpinning, especially in the field of environmental aesthetics. To put it in context, environmental aesthetics is a relatively new area of focus within the larger field of aesthetics that attempts to explore the aesthetic nature of things, conditions and activities that are not $\operatorname{art}^{11}$. Essentially, environmental aesthetics began as a way to understand how to appreciate things that are not made by human beings. Lately, as art practices have engaged with the Anthropocene, beginning with the Land Art movement onward, environmental aesthetics has also become concerned with "human-influenced" and "humanconstructed" environments that are neither art nor possibly architecture $^{12}$. While the emergence and contemporary importance of environmental ethics and aesthetics share an origin, which is the seismic shift from the anthropocentric to the eco-centric, they cannot coexist as they subversively but pervasively do in mainstream sustainable architectural practices $^{13}$.

Therefore, the generic undergraduate architectural curriculum needs to reassess its attitude towards the culture/nature binary that is so ingrained in the Western psyche. The author is continuing to develop a teaching pedagogy that asks how we might begin to work with nature vis-à-vis advances in digital design tools and digital fabrication. The title given to this ongoing teaching pedagogy and research agenda is Almost Natural. 


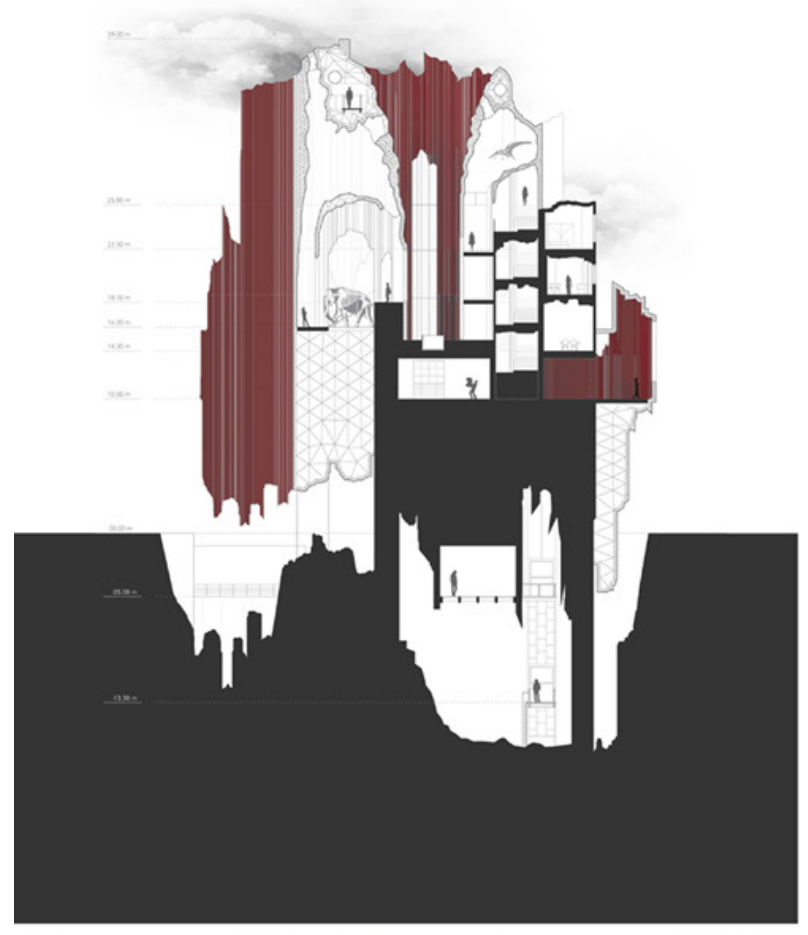

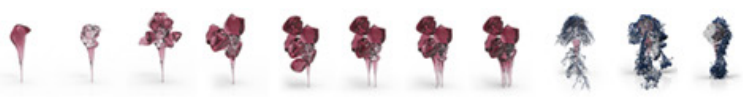

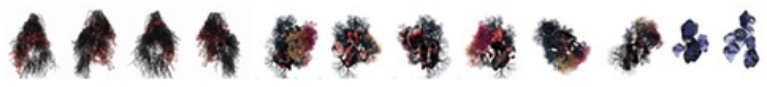

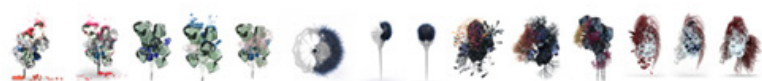

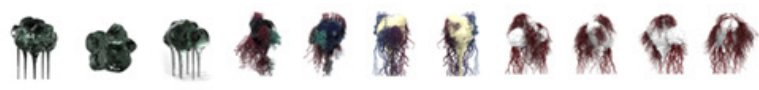
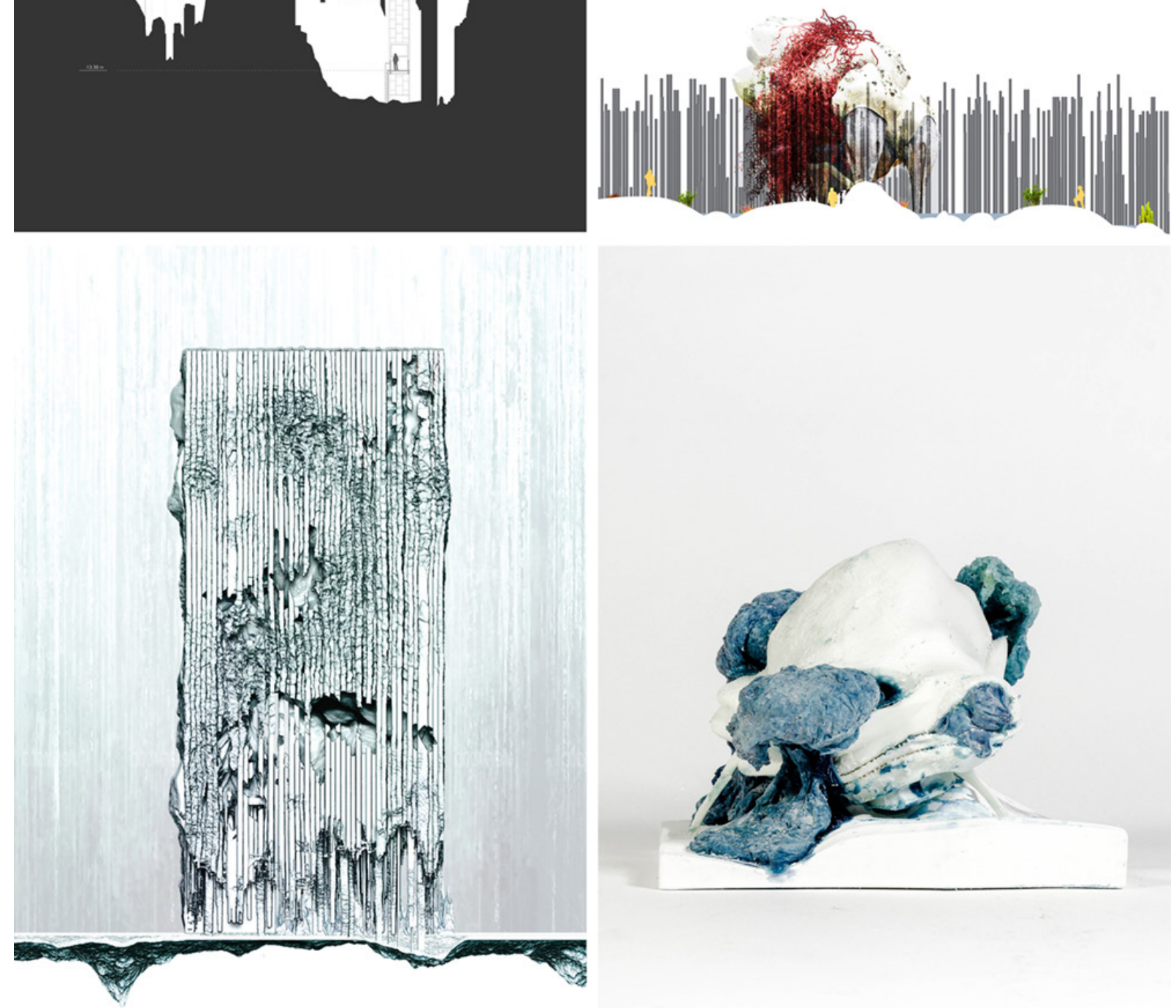


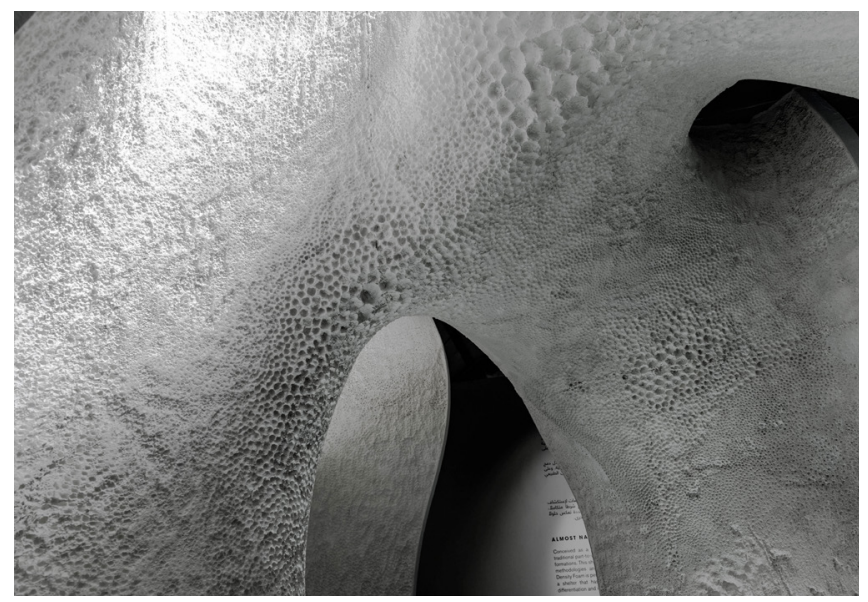

Figure 5: Work by the faculty member (author) that explores the issues deployed in the studio at a larger and spatial scale. (Photo Credits: Chito Pachica)

\section{AN ALMOST NATURAL PEDAGOGY}

This pedagogy aims to interrogate the production of space and aesthetics in the Anthropocene through exploring the relationship between computation, design, and material culture. Specifically, it describes a framework for an alternative and nebulous relationship between natural and synthetic things, one where computational design methodologies and different forms of digital and non-linear fabrications are deployed to create conditions that are Almost Natural.

In the development of the Almost Natural pedagogical model, there exists a conscious and active rejection of the historical othering of nature, due to the problems discussed above, in favor of a flattening between natural and man-made condition. The alternative that the pedagogy attempts to uncover consists of two interrelated parts, one material/technological, and the other spatial. The first goal aims at investigating the potential to deploy computational design methodologies to develop novel material assemblies that reject the hallmarks of traditional codified sustainable building practices such as part-to-whole relationships and precision in order to upend these practices. Albeit reactionary and polemic, this serves the goal of exploring a practice where emerging green aesthetics are not the only form of ethical architectural practice in the Anthropocene. The second goal aims at looking at the potential space types that emerge from these material assemblies.

As will be described below, and as can be seen from the student work examples, the material/technological dimension of this pedagogy has been explored more than the spatial dimension. The material conditions produced within this pedagogy exhibit formal conditions that reject traditional hierarchical constructions, clarity in part-to-whole relationships, pattern making, and precision. As it stands, work has been done to categorize the spatial affects produced by the diverse material assemblies and strategies. Moving forward, there are attempts at thinking about these issues more spatially from the inside out to better understand the potential for radically novel space types beyond spatial affects.

The student work and resulting constructs, which span the range of digital and material outcome, is being explored in two different sub-categories: (a) Material assemblies that exhibit a form of tactical organizations that assemble mis-fitting geometries (Figure 1 + Figure 3); (b) a blurring of part-to-whole relationships (Figure 2).

\section{MIF-FIT ASSEMBLIES}

The pedagogy being explored through this paper and through the student work and research accepts that architectural constructs cannot avoid the elemental reality of construction; essentially, that construction materials come in parts that have to be put together. Students are encouraged to focus on the reality that materials come in specific sizes and dimensions, hence, most construction occurs through the assembly of smaller elements into a larger whole. While the assembly methods vary from stacking to casting (which is in itself an assembly of elements), assembly in itself unavoidable. This position has also grown from a critique of prevailing notions of growth within computational design practices, where this growth is eventually expressed as a seemingly seamless 3D print. This does not preclude serious research that investigates the actual growing of materials, but this is outside the scope of this paper. This finds its way throughout all conversations in the design studio and beyond. The results of this is that students begin to productively shy away from what their preconceptions about nature-inspired design that implies ideas of growth and complex topological formations that have little to no direct application in contemporary architecture.

The teaching pedagogy attempts to identify elements of what constitutes an Almost Natural construction and resultant space type, one that rejects pattern in favor of extreme heterogeneity. Ideally, this pedagogy must prove itself at an architectural and inhabitable scale, thus, it must turn its attention to the tectonic assembly of smaller elements to create a larger whole (Figure 2 + Figure 3).

\section{NON-LINEAR FABRICATIONS}

One of the biggest tools within this pedagogy's toolbox is a specific messy attitude towards making that rejects traditional norms of precision and craft within an undergraduate architecture curriculum. In both their digital and physical workflows, students are encouraged to blur between the elements they are working with, which results in a blurring between the synthetic and the natural conditions at an architectural scale, due to its upending of contemporary expectations from construction. Specifically within the physical space, students explore a series of non-linear fabrication techniques such as casting resin into Styrofoam, melting wax, mixing sand and other materials to alter the 
behaviour of expandable foams, and expanding the volume of latex through heat (Figure 4). While the pedagogy does not outright reject typical fabrication methodologies, there is an inherent interest in attempting to understand the relationship between materials that do not usually work in tandem, such as resin and expanded polystyrene to create results that amplify texture in space. A question that this research proposal attempts to ask and uncover is the following: At a time where the natural and the synthetic have become ambiguous categories, can architecture be both natural and synthetic?

\section{PEDAGOGY DEPLOYMENT}

This teaching pedagogy continues to exist in three educational spaces: (a) As a 5th year graduating design studio; (b) as an ongoing theoretical underpinning used in teaching advanced computational design methodologies that includes a range of precise computational techniques and messy modeling workflows; (c) through a series of independent research courses with undergraduate seniors.

The diversity of deployment of this agenda comes from the author's goals to test it at multiple scales and in multiple spaces, both digitally and materially. For example, within the confines of the 5 th year graduating studio, the students are tasked with designing a residence for a collector that also doubles as a semi-public gallery (Figure 4). The typology is not very dissimilar to the Sir John Soane Museum. In these projects, students are asked to think about real-life material assemblies and how the agenda might challenge normative construction processes. The projects in this studio begin through a series of abstract drawings that take their cues from a series of lectures focused on the two sub-strategies introduced above (Misfit assemblies, blurred part-to-whole relationships). Figure (4) shows examples of this project at various stages of the process. For example, one can see a final building section where a distinction between natural and constructed ground are blurred to create spatial conditions that do not distinguish between the natural and the artificial. Figure (4) also shows how a series of early digital explorations into mis-fitting assemblies results in a residence/ gallery that integrates volumetric and linear elements in a strange landscape.

On the other hand, when deploying the pedagogy in the advanced computational design seminars, where the output is mainly digital but includes the potential of prototyping through 3D printing, the students are asked to think about large number of digital geometric elements as malleable natural material prone to mis-assembly and malleability. This cue is received strangely from the students at first, as working digitally has rendered their workflows towards precise and predetermined outcomes. However, simulating and encouraging an error prone environment in a digital design seminar has proved to open the door for solutions that overcome initial predeterminations. The focus in these seminars is on designing digital workflows that combine precise and messy applications to uncover the potential of the Almost Natural pedagogy digitally. Due to the constraints of these kinds of courses, the design requirements are kept controlled at the scale of a pavilion or a shelter than must engage with a natural ground condition. The first iterations of this exercise focused on exploring the misassembly of self-similar geometries, as can be seen from the top 2 rows of Figure (2), however, as the students have become better prepared technically as they enroll into these seminars due to an organic growth in technical competence across the curriculum, more complex scenarios are posed to them, as can be seen from the bottom left example in Figure (2), where a student explored integrating different kinds of geometries, or at the very least, similar geometries at a radically different scale.

Finally, when deploying this agenda within independent research courses, the students are encouraged to think about its applicability at a 1:1 scale. Due to the curricular limitations of such courses, the scale that seems to yield the most success is to design and construct a chair within one semester. Usually, these research project include developing a robust digital-to-physical workflow. In this context, the author also asks the students to critique his own work and research methodology to further push the pedagogy. For example, the project from Figure (3) is direct result of a critical analysis the student made on a number of the author's work.

Tangentially, within his own research, the author has attempted to deploy these ideas at a spatial scale in the form of a series of spatial pavilions. Thus, through teaching and research, the agenda has been tested at the scale of the building design project, digital workflow, furniture and pavilion. These shifts in scale continue to refine the criteria that defines success within the agenda as well as giving it a multidimensional trajectory.

\section{CONCLUSIONS AND FUTURE CONSIDERATIONS}

If Undergraduate architecture education wants to truly adopt a discourse about the Anthropocene, it must go far and beyond its current binary attitude guiding its teaching about society and nature, and by extension, architecture and the environment. This issue is far too complex to be solved by one pedagogical approach, and the one presented here is but one example of how teaching can ask students in the beginning design phase to rethink their preconceptions about nature. Difficult questions must be asked by architects, educators, students, and society in general when confronted with a crisis as global as the environmental crisis. In architecture, the central question is: How might we ethically design, build, and inhabit the Anthropocene. Adopting William Freudenburg's notion that nature and culture are part of a conjoined constitution, and by extension, that natural and synthetic constructs are not different from each other, might begin to uncover some potential answers to that question. 
The pedagogy set out two interdependent lines of inquiry to answer the central question above; inquiry into the material/technological dimension, and inquiry into the spatial. The student work described above has so far focused mainly on the material/technological aspects. For this to be a viable model, there needs to be a stronger spatial component to the results, especially that the paper and pedagogy set out a goal to uncover novel spatial conditions. This could work through posing more concrete architectural questions that deal with building design, and requesting more comprehensive design proposals. Another missing component is context. The projects shown above are lacking in external resistance, as they all exist within an imaginary large field. While the projects in Figure (4) had an actual site, it was largely flat and secluded. Therefore, sites with larger degrees of density will force the pedagogy, and the students to respond to spatial issues headon, and not accept the spatial conditions and affects that emerge as a result of material and technical mastery.

\section{ENDNOTES}

1 "Annual Energy Review." http://www.eia.gov/totalenergy/data/annual/ pecss_diagram.cfm. Accessed 10 October 2015.

2 "History: US Green Building Council." http://www.usgbc.org/about/history. Accessed 10 October 2015

3 McDonough, William. "Principles, Practices and Sustainable Design: Toward a New Context for Building Codes." Perspecta 35 - Building Codes, 2004. http:// www.mcdonough.com/speaking-writing principles-practices-and-sustainabledesign-toward-a-new-context-for-building-codes/\#.VjGN67crKgA. Accessed 15 October 2015.

4 A version of this paragraph, with additions and some alterations, comes from a previously published paper: Tabbarah, Faysal. 2015. "Almost Natural Things: Aesthetics and Production." In Proceedings for 2015 TxA Emerging Design + Technology, 2015, 88-99. Dallas: Texas Society of Architects.

5 Delancey, Craig. "Architecture Can Save the World: Building and Environmental Ethics." The Philosophical Forum: 147-159. Print.

6 Curry, Patrick. Ecological Ethics: An Introduction. Cambridge: Polity Press, 2006. p 1.

7 A version of this text, comes from a previously published paper: Tabbarah, Faysal. 2015. "Almost Natural Things: Aesthetics and Production." In Proceedings for 2015 TxA Emerging Design + Technology, 2015, 88-99. Dallas: Texas Society of Architects.

8 Freudenburg, William R. , Scott Frickel, and Robert Gramling. "Beyond the Nature/Society Divide: Learning to Think about a Mountain." Sociological Forum 10, no. 3 (September 1995): 361-92.

9 The National Architectural Accrediting Board, Inc. 2014 Conditions for Accreditation. P.16. 2014.

10 Lynch, Kevin and Gary Hack. Site Planning. The MIT Press, 1984. p 1.

11 Carlson, Allen. Nature and Landscape: An Introduction to Environmental Aesthetics. New York: Columbia University Press. p 1-2.

12 Carlson, Allen. Nature and Landscape: An Introduction to Environmental Aesthetics. New York: Columbia University Press. p 1-2.

13 A version of this paragraph, with additions and some alterations, comes from a previously published paper: Tabbarah, Faysal. 2015. "Almost Natural Things: Aesthetics and Production." In Proceedings for 2015 TxA Emerging Design + Technology, 2015, 88-99. Dallas: Texas Society of Architects. 